\title{
MEGA EVENT MANAGEMENT OF FORMULA ONE GRAND PRIX: AN ANALYSIS OF LITERATURE
}

\begin{abstract}
Purpose - A comprehensive literature review of mega event management of dynamic sporting events is presented. The purpose is to learn from these mega events to prescribe mitigation strategies for improving cost performance whilst simultaneously minimising public disruption on formula one grand prix events. Knowledge accrued of challenges posed is theoretically applied to circuit construction and reestablishment processes involved in orchestrating a 'street circuit' grand prix event.
\end{abstract}

Design/methodology/approach - An inductive research methodological approach was adopted using an interpretivist epistemological design. A mixed methods analysis of pertinent extant literature of mega events afforded greater synthesis of the research problem domain and generated more valid and reliable findings. The software VOS Viewer was utilised to conduct a qualitative bibliographic analysis of pertinent extant literature.

Findings - Three thematic groups of past research endeavour emerged from the analysis and were assigned appropriate nomenclature, namely: i) customer experience; ii) geographical location; and iii) research methods and approaches adopted. Analysis of these clusters revealed common factors that impact upon construction works during mega sporting events including: inclement weather conditions; miscommunication between project stakeholders; and economic impact upon the local community. Factors for mitigating these risks were also proposed including: traffic management plans; shift working; and wider public consultation.

Originality/value - This unique study provides invaluable insight into construction works commissioned and implemented at a mega 'motor sports' public event. Although the research context was narrowly defined, findings presented are equally applicable to contractors, organisers and public authorities orchestrating other types of public event. The research concludes with direction for future work that seeks to apply the lessons learnt and measure the impact of findings presented herein.

KEYWORDS - Mega Event Management, VOS Viewer, Logistics Management, Event Orchestration, Mitigation, Mega Sporting Event. 


\section{INTRODUCTION}

A mega sporting event can comprise of any type of sporting event of significant scale, including: Summer or Winter Olympics (Essex and Chalkley, 2004); Commonwealth Games (Carlsen and Taylor, 2003); FIFA World Cup (Lee and Taylor, 2005); Formula One Grand Prix (Gezici and Er, 2014); and MotoGP (Dolles and Söderman, 2008). Such events pay considerable dividends to spectators and organisers should they become commercial successes and as a consequence, they reflect well upon the hosting nation (Carlsen et al., 2010). However, organising and hosting a mega public event is a challenging feat for any organisation to undertake (Gursoy and Kendall, 2006) due to the extreme and dynamic logistical, technical and practical challenges encountered, where problems can arise unexpectedly (Malfas et al., 2004). For example, during the Super Bowl XLVII, hosted in the Mercedes-Benz Superdome in 2013, a power outage occurred (due to a defective electrical relay device) which caused the entire stadium to be plunged into darkness for twentytwo minutes and resulted in a thirty-four-minute stoppage mid-game (Hanna, 2013; Belson, 2013). Effective testing should have been conducted prior to the event's commencement to mitigate the risks posed (Pengelly, 2013). This example illustrates how failure to test systems and a lack of awareness of temperamental components can disrupt or halt a major event, in this instance due to a severe power loss. Such challenges must be overcome throughout an event's whole life cycle (i.e. before, during and after the event) as problems arising threaten non-continuation and can manifest in substantial penalty fines (Getz, 2008; Ellert et al., 2015).

The sheer scale of mega events also presents opportunities to innovate across a multitude of event management activities (ranging from programming, financial planning, stakeholder management, infrastructure provisions and events marketing) and to provide greater synchronicity between the event teams that organise these different aspects (Carlsen et al., 2010). Of the various mega sporting events, Formula One Grand Prix (FOGP) hosted on street circuits arguably poses the most significant risks (both financially and safety orientated) as it requires meticulous logistical planning and management (Cheng and Jarvis, 2010; Tng and Tan, 2012). Typical considerations include closing public areas and main thoroughfares and transforming streets into a viable track (Cheng and Jarvis, 2010). Producing minimal public disruption and ensuring public safety during the construction and reestablishment of the grounds is critical to event success, therefore logistical factors such as timing the closure of roads and public areas are vital (Springer, 2013). Because a 
street circuit is not a purpose-built racing track, many of the installations utilised during the race period are temporary and rely heavily upon impermanent means of statutory connections such as the electrical power supply to the track lighting system (Henderson et al., 2010). A failure in track lighting during the race would invariably prove to be commercially catastrophic and could endanger drivers and members of the public. Logistics are further exacerbated by the fact that event preparation for subsequent years' FOPG often commences shortly after the completion of the current event, hence additional layers of complexity are circumjacent to project processes and management (Thomas and Adams, 2005). Nevertheless, and despite the significant logistical challenges posed, street circuit events represent a highlight of the FOGP calendar and are an integral part of the Fédération Internationale de l'Automobile F1 World Championship (Low, 2009; Todd et al., 2015; Næss, 2017).

Non-disclosure agreements (NDAs) typically enshroud mega event management for a FOGP, causing an invaluable opportunity for optimising future events to be forfeited. Indeed, the vast majority of contemporary research conducted in the area of hosting a grand prix event has focused upon marketing and marketing brand as well as the social, economic and environmental impact of such events from an independent perspective. For example, Quester and Farrelly (1998) examined brand recall/association and memory decay whilst Quester (1997) reviewed the effectiveness of sponsorship. Henderson et al. (2010) focused upon tourism to assess the socio-economic impact of a grand prix event held in Singapore whilst later Fairley et al. (2011) questioned the socioeconomic and environmental impact of hosting a mega event. Moreover, Zhou (2010) and Fairley (2011) raised concerns about government financial support for motor sport events and whether such was viable. More recently, Kim et al. (2017) examined the pure economic impact of hosting a grand prix event. Cumulatively, this body of knowledge accrued fails to cover the actual orchestration itself.

Against this contextual backdrop, the research undertaken specifically focused therefore upon conducting a comprehensive review of extant literature on major event organisation per se as a means of overcoming restrictions imposed by NDAs. Concomitant research objectives were to: i) identify barriers to a successful event orchestration with the intention of implementing risk mitigation strategies to prevent or ameliorate the effects of issues should they arise; and ii) discuss 
the findings of the research undertaken but also propose future research to address a current dearth of investigation in this field of management science. The aim of fulfilling these objectives is to help optimise resource management and engender swift mobilisation, response and rectification to unexpected issues that arise during the FOGP. Given that the research presented constitutes an analysis of literature, the paper commences with a research approach that defines and delineates the methods to be adopted - this design departs from a traditional paper that commences with a literature review.

\section{RESEARCH APPROACH}

An inductive research methodological approach was adopted using an interpretivist (with elements of positivist) epistemological design (Aristizabal, 2016). Within this overarching approach, a mixed methods research design was adopted to analyse extant literature; where literature represented the sample data (Liping and Hsing-Hui, 2017). Both qualitative and quantitative data were used to allow a greater synthesis of the research problem domain and generate more valid and reliable findings (Green et al., 2014). An iterative three-stage literature review was then conducted; namely: i) a broad review of literature to set the research study's context; pertinent topics were covered in the sections entitled 'impact assessment of mega events' and the 'planning and management of a FOGP'; ii) a manual literature search to identify project complexity issues and sub-complexity issues within the section entitled 'project dynamism and complexity'; and iii) a qualitative componential analysis of existing extant literature using terminologies identified, which were subsequently input into the software VOS Viewer (refer to the section entitled 'VOS viewer findings'). A componential analysis is a manual technique that assigns the meaning of a word(s) or other linguistic unit(s) to discrete semantic components (van Grootel et al., 2017; Fisher et al., 2018). VOS Viewer was utilised for constructing visual bibliometric networks using for example, researchers and scholars, journals and theses. The proposed bibliometric analysis was extracted and collated from the 'Web of Science' (WoS)' database. WoS contains a 'core collection' of databases and encompasses a significantly wide range of academic journals and scientific research papers/reports in the field of events management and hospitality. To ensure that only relevant academic literature was retrieved for subsequent bibliometric analysis, keywords from the published research reviewed were utilised. These keywords were: events, management, hospitality and mega. A three tiered approach to constructing bibliographic networks was adopted 
that sought to: a) identify key authors within the field; b) ascertain the global geographical spread of pertinent research conducted; and c) identify key terminologies on barriers, enablers and potential solutions to optimising mega event management of a FOGP. Post analysis, a discussion of the findings was implemented.

This methodological approach adopted helped to identify areas of event project management that are currently being investigated in order to: i) determine whether transference of best practice from other major events to grand prix events is achievable; and ii) highlight any voids in contemporary knowledge on mega event management. Identification of these voids enables future research to be signposted. The findings of the literature analysis are as follows.

\section{IMPACT ASSESSMENT OF MEGA EVENTS}

Mega events are classified as major one time or recurring events of limited duration, developed primarily to enhance the awareness, appeal and profitability of a tourism destination (Ritchie and Crouch, 2006). These events must fulfil four prerequisites for them to be classified as such, namely to: i) be of a fixed duration; ii) attract an extremely large number of people; iii) appeal to large media outlets that broadcast the event globally; and iv) create direct inward investment in the host country in the form of new infrastructure, economic growth and urban renewal (Horne and Manzenreiter, 2006; Zagnoli and Radicchi, 2009). The FOGP fulfils all these pre-requisite requirements, but hosting the mega event facilitates a range of positive and negative impacts - the host nation's dilemma is how to augment the positive impacts whilst concurrently ameliorating negative impacts (Muller, 2015).

\section{Positive Impacts}

Event tourism is the natural outcome of hosting a mega event and is a primary driver in developing premier destination hotspots that enable a country to revitalise itself (Zagnoli and Radicchi, 2009; Boes et al, 2016). Furthermore, countries that demonstrate an aptitude to orchestrating hugely complex events will invariably attract new stakeholders to host additional ones (Chen, 2012). Mega events are catalysts for economic growth, attracting a sizeable influx of visitors and their spending (Getz, 1997). This influx generates significant regional economic impact and any temporary disruption created is deemed worthwhile provided the heightened expenditure (by 
patrons and tourists) supports local businesses. Additionally, the creation of permanent and temporary employment (especially in hospitality and events management sectors) provides greater business and employment opportunities for local residents (Andersson et al., 2008). For example, the Singapore FOGP in 2018 was expected to attract more than 450,000 spectators and a projected S\$1.4 Billion in incremental tourism receipts (Meng, 2017).

\section{Negative Impacts}

Conversely, the negative effects of hosting mega events may include increased inflation and governmental taxation (Liang et al., 2016). Inflationary pressures can engender extreme rises in the standard cost of living for local residents who may not directly benefit from the temporary infrastructure and facilities constructed for a FOGP event (Coates and Matheson, 2009). For example, accommodation rates skyrocket for foreign visitors expecting to catch a glimpse of the FOGP and therefore, certain demographics are effectively priced out of attending such events.

\section{PLANNING AND MANAGEMENT OF A FOGP}

The geographical location of a FOGP event may provide unique meteorological hazards that are peculiar to that country. For example, in a tropical climate frequent thunderstorms and excessive rainfall can wreak havoc upon infrastructure and electrical works - such natural 'force majeure' events are difficult to mitigate against. Consequently, climate prediction and forward preparation of suitable mitigation strategies is vital to achieving a successful event orchestration. In addition, event organisers actively seek to develop new consumer experiences year-on-year that will showcase the event in a new light, with ambitions to: keep exist patrons captivated; attract new customer demographics; and increase consumer spending (Ramchandani, 2017). These experiences could include new trackside activities, larger capacity entertainment venues and more refined hospitality suites for spectators. Creating a more vibrant and opulent atmosphere for a FOGP seeks to attract a greater influx of race attendees (Fhoong, 2017). In terms of preparing and staging the event itself, an expanded event will create additional workload to schedule the construction and reestablishment of any temporary infrastructures. Stringent programme timescales and immovable deadlines stipulated for circuit and facilities delivery have made carefully coordinated night work arrangements justifiable for many circuits. However, night environments reduce visibility for the workforce even with supplementary artificial lighting. 
Therefore, works scheduled during this period should require a lesser degree of workmanship because highly skilled tasks such as fitting out hospitality suites would not produce the quality finish expected (Shepard and Cottrell, 1986).

For temporary city circuits, most track components are stored offsite in satellite factories. During circuit construction, the delivery of track components increases the risk of damage occurring during transit, resulting in additional cost for repairs or commissioning of new components to be manufactured (Barretto, 2013). In addition, and outside the racing season, a large proportion of the circuit track is for public motorists and subject to general wear and tear which requires intensive reinstatement and repair before and after the FOGP event (Collins and Ireland, 2007). Managing the transport of components and materials is pivotal to the construction programme and a key consideration is that components are delivered on site just-in-time (cf. Minou et al., 2017). That is, not too early (leaving them susceptible to additional damage) and not too late (risking a delay to the projects programme). This myriad of additional elements that need to be effectively and efficiently programmed and assembled over the build-up, construction and reestablishment periods for a FOGP event present opportunities for the event's management to falter.

\section{PROJECT DYNAMISM AND COMPLEXITY}

A major concern for the organisers of a FOGP event is any changes that may arise and the management of these during the project's life cycle (Hwang and Low, 2012). Such works create uncertainty (Guido et al., 2015) and could include: additional requirements; omission of works; and/ or modifications to existing scope of works by stakeholders - all of which cause project disruption (Hwang and Low, 2012; Charles et al., 2016). The uncertainty of potential changes creates a dynamic environment within which mega events are orchestrated and elevates the risk of such events becoming unstable (Collyer and Warren, 2009). Because mega events operate within fluid environments that invoke greater project dynamism (c.f. Shenhar and Wideman, 2000), they can be classified in relation to complexity and types of technology used during the project life cycle. FOGP events are classified as 'high-tech' because the grand prix has developed and implemented advanced systems and technologies over time to attain operational efficiencies and mitigate risks that plagued inaugural events (Collyer and Warren, 2009). This degree of project complexity is further exacerbated by the interrelation of numerous sub-projects which must be 
delivered in synchronicity to achieve a successful orchestration (Giezen, 2012). These sub-projects are inextricably interwoven with each other due to logistical, geographical and managerial restrictions - therefore, non-accomplishment of one sub-project can instigate failure of the entire project (Zeng et al., 2007). For example, the PyeongChang 2018 Winter Olympics (held from $9^{\text {th }}$ $-25^{\text {th }}$ February 2018) was a prime example of a mega event of exponential magnitude comprising of a series of miniature projects that required appropriate planning, execution and management to ensure that established deadlines were accomplished (Ceil, 2015).

An extensive manual review of extant literature on the topics of project/programme management, event management and hospitality studies identified a number of project complexity factors that were clustered into thematic groups, namely: structures and infrastructure; track and civil installation; event facilities and amenities; power/ communications/ lighting; health and safety; and miscellaneous. Further analysis of the factors enabled a more detailed identification of construction and reestablishment issues. For example, under the 'track and civil installation' group, sub-complexity issues identified include: track barrier installation; track cleaning; ground protection; and civil issues (such as the storage of plant and materials, implementation of traffic management devices and installation of temporary pavements/ramps to existing road surfaces). Table 1 presents a complete account of all the thematic groupings of complexity issues and subcomplexity issues. These issues demonstrate that members of the events management team must possess a varied range of skills, expertise and knowledge of project complexity issues.

\section{<Insert Table 1 about here>}

\section{VOS VIEWER FINDINGS}

A VOS Viewer network was created using a nodularity based clustering technique to illustrate prominent authors who have published in the field of mega events management and hospitality studies. The author field was extracted from the WoS data file and the frequency of occurrence displayed on a digital 'nodular' map. Research articles selected for review were peer reviewed academic journal papers published between 2008-2018. WoS initially returned 189 relevant papers for entry into the VOS Viewer software to create a visual network based on paper authorship and co-citations of authors. In Figure 1 nodes of varying size proportionally depict the number of 
occurrences and co-occurrences of citations and co-citations used by the publications' authors. The most prominent author with the highest visible weighting is Donald Getz, a renowned academic from Haskayne School of Business, University of Calgary, Canada. Getz's research focuses upon international tourism and event-studies but he has specific expertise in: evaluation and impact assessment of events by residents and stakeholders; and strategic planning for tourism and events. Prof. Dogan Gursoy from the School of Hospitality Business Management, Washington State University, United States of America (USA) is another influential academic scholar identified whose focus is upon international tourism and hospitality management. These two prominent authors have numerous interconnectivities with scholars in the centre and periphery of the cluster map.

$<$ Insert Figure 1 about here>

VOS Viewer states that nodes that have a smaller distance between them signify a stronger relationship. This is illustrated in Figure 1 by the two defined clusters of connected authors around the work of Getz and Gursoy and demonstrates how these two scholars have spearheaded research in the field of events management and hospitality. Their work has been further augmented and proliferated by other academics in order to branch out into more niche areas, which can be seen by the nodes spreading further away from the clusters.

The data was also extrapolated using the geographical zones from which academic papers originated, in order to geographically map the contributions of pertinent authors, This analysis illustrates the extent to which authors from different countries utilise bibliographic coupling (which occurs when two works reference a common third work within their bibliographies) - refer to Figure 2.

$<$ Insert Figure 2 about here>

The spatial cluster diagram denotes numerous nodes for which the size of each is weighted proportionally to represent each country's contribution to publications in mega events management but also which countries have published academic papers that are commonly referenced by more 
than one other party. Those countries exhibiting a greater density of contributions includes the USA, England and the Peoples Republic of China (PRC); this geographical dispersion suggests that research on this subject is attractive to countries across all continents. A geographical breakdown of paper contributions by relevant nations is reproduced in Table 2 and this information is visualised in Figure 3 for completeness; these regions range from the greatest to smallest aggregate contributions to this research field. On a continental level, the highest number of contributions derive from North America, Central Europe and Far East Asia. On a national level, the developed nations of South Korea, Australia, PRC, the United Kingdom and USA have the highest distribution of academic papers published - note that where co-authorship may have occurred, academic papers may have been allocated to more than one region specifically. This finding is perhaps unsurprising when considering that these developed nations regularly host annual and one-time mega events such as the recent PyeongChang 2018 Winter Olympics.

\section{<Insert Table 2 and Figure 3 about here>}

To understand the true complexity of mega event management, an additional bibliographic analysis was undertaken of key terminologies over a period of time (2013-2015) to help elucidate upon any potential shifts in research focus. These key terminologies (ranging from economic, environmental and social factors) help the event's team to decide: how each particular instance of a FOGP is run; how logistical plans are constructed; and what incentives (typically 'attractions') are available to entertain local residents and foreign nationals through this potentially disruptive period in the calendar year. Field titles and paper abstracts were used to locate terminology relevant to the study, of which a total of 4,083 terms had co-occurrences across published academic papers. To formulate a network with only the most relevant terminology utilised, a filter was applied to the results, where each term displayed needed to have a co-occurrence factor of 15 or more, i.e. a specific term must appear within at least 15 different academic papers. Consequently, the initial 4,083 returned results were reduced to 83 terms, as displayed in Figure 4. This figure illustrates that the largest concentration of recent research has focused upon methodological approaches adopted - for example, prominent exemplars include case study, design and methodology approach. Social impact of the event and geographical location were also extensively studied. Interestingly, the figure illustrates that during the period studied, there was a significant shift in 
research focus from economic and tourism benefits to a city/country hosting a mega event, to the practical and social implications that effect residents when hosting mega events.

<Insert Figure 4 about here>

Notably the findings also illustrate that research into the actual physical construction and planning of FOGP events is conspicuous by its absence within the existing body of knowledge. Rather, the prevailing discourse predominantly focuses upon business and marketing issues pre-, during and post-event.

\section{Barriers, Enablers and Potential Solutions}

The bibliographic network was further examined through consideration of the key titles, abstracts and terminology from extant literature to generate a textual conceptualisation that segregated key 'barriers and enablers' terminology into colour coded 'thematic' groups (refer to Figure 5). Four interrelated groupings were identified and were colour coded as Red (R), Green (G), Blue (B) and Yellow (Y). Upon closer inspection of Figure 5, arbitrary nomenclature could be assigned to each grouping based upon the predominant content of each cluster. Hence, group R was assigned as customer experience, group $\mathrm{G}$ as geographical location and groups B and Y were amalgamated as research methods and approaches adopted.

\section{$<$ Insert Figure 5 about here>}

\section{Clusters B and Y-Research Methods and Approaches Adopted}

Research methods and approaches adopted have been extensive and include: case studies (Andreas, 2003); reviews of spectators' experiences (Kruger and Saayman, 2012); and cultural perspectives (Christou, et al., 2018). Cumulatively, a multitude of large-scale/mega events have been investigated (including sports, music festivals and concerts) and similarities between approaches adopted are apparent. For example, project management plans must be implemented by the respective organising teams before stakeholder approval can be gained. It is also apparent that future hosts of mega events are acutely aware of the outcomes of previous case studies, together with the success or otherwise of such events. In particular, event organisers and academics 
have sought to identify barriers and enablers that led to the success or otherwise of a major event (Mills and Rosentraub, 2013). Particular attention has been paid to critical faults or oversights, together with any remedial action implemented to rectify these as lessons learnt (Black and Plowright, 2010). Such introspection demonstrates that event organisers acknowledge the importance of past event analysis as a fundamental mitigating strategy for shaping future event profitability/commercial success.

\section{Cluster G-Geographical Location}

Socio and socioeconomic impacts are crucial to running a major event and these considerations can be conveniently grouped under the heading of geographical location (Gaffney, 2010). Interestingly, research conducted illustrates that during major events the local area may ironically experience economic loss ( $\mathrm{Li}$ et al,. 2013). For example, during the Singapore Grand Prix, local businesses located along the racetrack suffered from a reduction in footfall due to road access and footpath restrictions during the track installation (Karadakis et al., 2010). If local citizens become dissatisfied with the disruption that the orchestration and reinstatement works cause, potential boycotting of the event could occur. To avoid dissent, the public must be consulted and appropriate risk mitigation strategies developed. As a potential solution, local authorities should set stringent guidelines on which thoroughfares can be closed and at what time. Effective coordination is crucial and should involve three-way communication between the project management team, stakeholders and the client to ensure that an accurate and effective road closure plan is produced as part of a traffic management plan (TMP). During installation of circuit track barriers, road closures during the night are proven to be more effective as traffic volume drops significantly with workers and families at home. Cyclical review of the TMP will highlight any efficiencies and/or deficiencies apparent. For recurrent FOGP events, year-on-year increased stringent deadlines are imposed due to familiarity with the existing installation and remediation processes involved (i.e. closing main public roads as late as possible and reopening as expediently and safely as possible). To aid local businesses affected by the TMP, reassurance to the public is needed that: i) local businesses are open and trading; and ii) members of the public are physically prevented from inadvertently wandering into a potentially hazardous area due to the ongoing construction works. 
Running a successful FOGP event for a number of consecutive years in the same location does not guarantee it will retain its continual appeal without sacrificing some elements and incorporating new features into the packages that are offered to tourists, prospective guests and VIPs. Continual upgrade of the hospitality suites is needed to avoid 'repetitiveness creep' and at each event VIP attendees should luxuriate in new experiences for which event promotion will spread virally if received well (Ekinci et al., 2008). Enlarging the experience packages can significantly increase expenditure due to the manufacturing and labour processes involved in fabricating new hospitality suites, grandstands and upgraded entertainment arenas (Yang and Mattila, 2016). However, failure to continually improve the event could similarly jeopardise its future viability (Leopkey et al., 2013).

\section{Cluster R Customer Experience}

The customer experience cluster conveys weaker interconnectivities when compared to the other clusters identified and so future work is needed to interrogate this cluster further and in isolation. Nonetheless, some interesting emergent findings are apparent. For example, stakeholders can initiate changes within the programme due to a variety of factors such as inclement weather (Ma et al., 2011) and/or last minute client changes/finishing touches (Assaf and Al-Hejji, 2006). Last minute changes are usually implemented to provide the high-quality finish that spectators and sponsors expect (Smith, 2013). These frequent occurrences throughout the FOGP life cycle are

anticipated and in order to pre-plan, a project management team should identify and forecast opportunities for change within an effective mitigation strategy. Variances to the project programme bear an inherent cost which escalates exponentially the further the project programme progresses to completion (Asiedu et al., 2017). These variations are generally unknown in advance (or considered during the design process) and are normally the result of on-site inspections identifying further improvement works (Muller, 2015). Due to the dynamic nature of a FOGP project, a quick response unit is needed to effectively and efficiently manage client/stakeholder changes into the track and surrounding circuit.

\section{DISCUSSION}

The analysis reveals a plethora of factors that could potentially disrupt successful FOGP event orchestration, the status of the local economy and the trickle-down effect upon the liquidity of 
multi-national corporations that provide invaluable sponsorship funding, where the latter is vital to planning and managing mega events. The capital required to run a recurrent FOGP year-on-year should fall due to the linearity and repetitiveness of the orchestration and reinstatement processes, despite a natural rise in inflation. This is partly due to the exclusive use of selective 'specialist' contractors and subcontractors whose experience and knowledge of circuit construction ensures that initial expenditure is sustained at a low level - in turn, this allows capital and resources to be diverted to more risk adverse and time bound areas of the FOGP orchestration process. However, repeated usage of selective contractors increases the risk that such companies demand greater reimbursement given their expertise in orchestrating and hosting a live global night-time race. Diversifying the workforce by including local contractors could represent a viable risk mitigation strategy and be beneficial to the local economy as well as stimulating further growth locally and city state wide. By encouraging global workforces to compete with local contractors, costs should be driven down to the benefit of the stakeholders without sacrificing the quality of the workforce utilised.

Ultimately, the discussion and analysis presented is somewhat hypothetical as it is predicated upon the past experiences of research conducted in similar events. Future deductive (and longitudinal) research is therefore needed to apply the lessons learnt from the literature to the FOGP and measure the outcomes of such changes - perhaps as part of participant action research? Such work could assess and analyse the impact of project process change management and how it mitigates potential problems regarding the running of the FOPG. In turn, this formative work could form the basis for an intelligent system that is capable of highlighting specific sectors of problematic track throughout the F1 period (including track, barrier, power and facilities installation). For example, a hybrid version of 'systems dynamics' (c.f. Khan et al., 2016) augmented with 'generic algorithms' (c.f. Kadri and Boctor, 2018) could be utilised to optimise decision making during mega event operations management. Other techniques and methodologies could be equally applicable but the choices will be dependent upon the nature of data collected.

A fundamental problem resides in the presence of NDAs that are used to tailor confidentiality obligations by parties entering an agreement (De Cleyn et al., 2015). Amongst other things, NDAs define what information should remain confidential and delineate the consequences of breaching 
the agreement (Marx, 2011). However, NDAs that prevail within the events sector (and indeed, which impacted upon this research) significantly reduce the opportunity to independently collect meaningful primary data that is required to investigate events orchestration in a transparent manner and/or learn vital lessons from mistakes or successes made - tension is apparent between ambitions to share knowledge with external partners and a necessity to protect invaluable corporate intelligence/know-how (Aloini et al., 2017). There is also a propensity for individuals within a project management or client team to leak sensitive information that may have a financial value in such instances, the organisation's ability to defend its intellectual property is compromised (Hannah and Robertson, 2014). Consequently, it could be argued that the benefits of greater transparency outweigh any disadvantages posed.

\section{CONCLUSIONS}

Hosting a mega sporting event can provide many palpable economic, social and cultural benefits should it become a commercial success. Included amongst these are: employment opportunities for local people; long term infrastructure investment for the host city and/or nation; short term economic growth from investors and foreign tourists; and augmented national profile and enthusiasm of the populous. However, organising and hosting a mega public event is a challenging feat for any organisation to undertake because organisers face extreme and dynamic logistical, technical and practical challenges where problems can arise unexpectedly. Such challenges can expose the event to various disadvantages such as: the high costs incurred not being adequately covered by income generated; tax hikes to cover costs incurred; the short term use of building and infrastructure and its impact upon the environment; and negative publicity.

A synthesis and analysis of existing literature on mega event management highlights the need to meticulously forward plan the event in close consultation with all stakeholders and prepare disaster plans to deal with unforeseen emergencies that may occur. The sheer size, complexity and dynamic nature of mega event management requires employment of a highly experienced/competent project management team well versed in past events orchestrated. However, the tacit knowledge of mega sporting event managers is sparse within the literature even though it is clear that aspects of such are funded and researched periodically (particularly in terms of 'marketing' and 'brand recognition' for associated event sales and sponsorship purposes). This notable dearth of wisdom limits event 
organisers' ability to augment and improve upon past performance as frequently only short term commercial success is measured vis-à-vis longer term economic, cultural and societal prosperity. Matters are further exacerbated by stringent NDAs that prevent further academic investigation and analysis of a live event, or longitudinal study, from being undertaken. Such is one of the limitations of this present study. Consequently, future work is required to: present the research findings to mega event management teams to secure practitioner input as a first step towards securing a collaborative memorandum of understanding; and conduct participant action research (as part of a longitudinal study) and intervention analysis to measure the success or otherwise of recommendations made within this research. Lessons learnt would provide useful 'best practice' benchmark reference materials for other event organisers to share and benefit from as part of a larger community of practice. They would also help to develop more robust mitigation strategies to attenuate mega event orchestration problems in present and future projects. 


\section{REFERENCES}

Aloini, D., Lazzarotti, V., Manzini, R. and Pellegrini, L. (2017) IP, Openness, and Innovation Performance: an Empirical Study, Management Decision, Vol. 55, No. 6, pp. 1307-1327.

Andersson, T., Armbrecht, J. and Lundberg, E. (2008) Impact of Mega-Events on the Economy, Asian Business and Management, Vol. 7, No. 2, pp. 163-179.

Anon. (2017) F1 Successes go Beyond the Track, The Straits Times. Available Via: Http://Www.Straitstimes.Com/Opinion/F1-Successes-Go-Beyond-The-Track [Accessed: November 2017].

Anon. (2017) Singapore F1 - Formula 1 Night Race - Singapore Grand Prix, Singaporegp.Sg. Available Via: Http://Www.Singaporegp.Sg/Media/Press-Release/236 [Accessed: November 2017].

Anon. (2017) Singapore Grand Prix 2017, Red Bull. Available Via: Https://Www.Redbull.Com/Sg-En/Events/Singapore\%20grand\%20prix\%202017 [Accessed: November 2017].

Andreas, M.R. (2003) Validity and Reliability Tests in Case Study Research: A Literature Review With Hands-On Applications for Each Research Phase, Qualitative Market Research: An International Journal, Vol. 6, No. 2, pp. 75-86.

Aristizabal, A.F. (2016) An Epistemological Approach for Research in Educational Data Mining, International Journal of Education and Research, Vol. 4, No. 2, pp. 131-138.

Asiedu, R., Adaku, E. and Owusu-Manu, D. (2017) Beyond the Causes - Rethinking Mitigating Measures to Avert Cost and Time Overruns in Construction Projects, Construction Innovation, Vol. 17, No. 3, pp. 363-380.

Assaf, S. and Al-Hejji, S. (2006) Causes of Delay in Large Construction Projects, International Journal of Project Management, Vol. 24, No. 4, pp. 349-357.

Barretto, L. (2013) Singapore Gp: How Do You Turn Marina Bay into an F1 Street Race? Available Via: Http://Www.Bbc.Co.Uk/Sport/Formula1/24127798 [Accessed: March 2018].

Belson, K. (2013) Super Bowl - Power Failure Delays Game, Nytimes.Com. Available Via: Http://Www.Nytimes.Com/2013/02/04/Sports/Football/Power-Outage-In-SuperdomeDelays-Super-Bowl.Html [Accessed: November 2017]. 
Black, P. and Plowright, D. (2010) A Multi-Dimensional Model of Reflective Learning for Professional Development, Reflective Practice, Vol. 11, No. 2, pp. 245-258.

Boes, K., Buhalis, D. and Inversini, A. (2016) Smart Tourism Destinations: Ecosystems for Tourism Destination Competitiveness, International Journal of Tourism Cities, Vol. 2, No. 2, pp. 108-124.

Browning, G. (2016) Spectator Comfort in Grandstands - An Alternative Approach, Proceedings of the Institution of Civil Engineers - Structures and Buildings, Vol. 169, No. 8, pp. 595610.

Carlsen, J. and Taylor, A. (2003) Mega-Events and Urban Renewal: The Case of the Manchester 2002 Commonwealth Games, Event Management, Vol. 8, No. 1, pp. 15-22.

Carlsen, J., Andersson, T., Ali-Knight, J., Jaeger, K. and Taylor, R. (2010) Festival Management Innovation and Failure, International Journal of Event and Festival Management, Vol. 1, No. 2, pp. 120-131.

Ceil, C. (2015) The Process of Project Managing the 2012 London Olympic Games. SSRN Electronic Journal. Available Via: https://papers.ssrn.com/sol3/papers.cfm?abstract_id=2571153 [Accessed: January 2018].

Charles, S. P. R., Wanigarathna, N. and Sherratt, F. (2015) Construction Project Change: Investigating Cost and Benefits, in 31st Annual ARCOM Conference (pp. 833 -842). Lincoln, UK: Association of Researchers in Construction Management.

Cheng, E. and Jarvis, N. (2010) Residents' Perception of the Social-Cultural Impacts of the 2008 Formula 1 Singtel Singapore Grand Prix, Event Management, Vol. 14, No. 2, pp. 91-106.

Christou, P., Sharpley, R. and Farmaki, A. (2018) Exploring the Emotional Dimension of Visitors' Satisfaction at Cultural Events, Event Management, Vol. 22, No. 2, pp. 255-269.

Coates, D. and Matheson, V. (2009) Mega-Events and Housing Costs: Raising the Rent While Raising the Roof? The Annals of Regional Science, Vol. 46, No. 1, pp. 119-137.

Collins, S. and Ireland, G. (2007) Autodrome, Dorchester: Veloce.

Collyer, S. and Warren, C. (2009) Project Management Approaches for Dynamic Environments, International Journal of Project Management, Vol. 27, No. 4, pp. 355-364.

De Cleyn, S.H., Meysman, J. and Braet, J. (2015) A Critical Assessment of the Non-Disclosure Agreement in the Framework of the Technology Transfer Process: A Longitudinal Study, Journal of Private Equity, Vol. 18, No. 2, pp. 39-51. 
Dolles, H. and Söderman, S. (2008) Mega-Sporting Events in Asia - Impacts on Society, Business And Management: An Introduction, Asian Business and Management, Vol. 7, No. 2, pp. 147-162.

Ekinci, Y., Dawes, P. and Massey, G. (2008) An Extended Model of the Antecedents and Consequences of Consumer Satisfaction for Hospitality Services, European Journal of Marketing, Vol. 42, No. 1/2, pp. 35-68.

Essex, S. and Chalkley, B. (2004) Mega-Sporting Events in Urban and Regional Policy: A History of the Winter Olympics, Planning Perspectives, Vol. 19, No. 2, pp. 201-204.

Fairley, S., Tyler, B.D., Kellett, P. and D'Eliaa, K. (2011) The Formula One Australian Grand Prix: Exploring the triple bottom line, Sport Management Review, Vol. 14, No. 2, pp. 141152. DOI: https://doi.org/10.1016/j.smr.2010.07.001

Fhoong, L. (2017) The Big Read: To Keep Roaring for S'pore, F1 Needs To Raise Its Game. Todayonline. Available Via: Http://Www.Todayonline.Com/Sports/Big-Read-KeepRoaring-Spore-F1-Needs-Raise-Its-Game [Accessed: November 2017].

Fisher, L., Edwards, D. J., Pärn, E. A. and Aigbavboa, C. O. (2018) Building Design for People with Dementia: A Case Study of a UK Care Home, Facilities, Vol. 36, No. 7/8, pp. 349368.

Gaffney, C. (2010) Mega-Events and Socio-Spatial Dynamics in Rio De Janeiro, 19192016, Journal of Latin American Geography, Vol. 9, No. 1, pp. 7-29.

Getz, D. (1997) Event Management and Event Tourism. New York: Cognizant Communications Corporation.

Getz, D. (2008) Event Tourism: Definition, Evolution, and Research, Tourism Management, Vol. 29, No. 3, pp. 403-428.

Gezici, F. and Er, S. (2014) What Has Been Left After Hosting The Formula 1 Grand Prix in Istanbul?, Cities, Vol. 41, pp. 44-53.

Grant, M.P. (2016) Healthcare and Commercial Construction: The Role of Inspections Within Health And Safety Interventions in Dynamic Workplaces and Associations With Safety Climate. Doctoral Dissertation, Harvard T.H. Chan School of Public Health.

Green, C., Duan, N., Gibbons, R., Hoagwood, K., Palinkas, L. and Wisdom, J. (2014) Approaches to Mixed Methods Dissemination and Implementation Research: Methods, Strengths, 
Caveats, and Opportunities, Administration and Policy in Mental Health and Mental Health Services Research, Vol. 42, No. 5, pp. 508-523.

Guido, E., Guido, S., Wawrzinek, D. and Gassner, H. (2015) Expect The Unexpected: New Perspectives on Uncertainty Management and Value Logics in Event Management, International Journal of Event and Festival Management, Vol. 6, No. 1, pp. 54-72.

Gursoy, D. and Kendall, K. (2006) Hosting Mega Events, Annals of Tourism Research, Vol. 33, No. 3, pp. 603-623.

Hanna, J. (2013) Manufacturer Blames Super Bowl Outage on Incorrect Setting - CNN. Available Via: $\quad$ Http://Edition.Cnn.Com/2013/02/08/Us/Superdome-Power-Outage/Index.Html [Accessed: December 2017].

Hannah, D.R. and Robertson, K. (2014) Why and How Do Employees Break and Bend Confidential Information Protection Rules?, Journal of Management Studies, Vol. 52, No. 3, pp. 381-413.

Henderson, J., Foo, K., Lim, H. and Yip, S. (2010) Sports Events and Tourism: The Singapore Formula One Grand Prix, International Journal of Event and Festival Management, Vol. 1, No. 1, pp. 60-73.

Horne, J. and Manzenreiter, W. (2006) An Introduction to the Sociology of Sports MegaEvents, The Sociological Review, Vol. 54, No. 2, pp. 1-24.

Hwang, B. And Low, L. (2012) Construction Project Change Management in Singapore: Status, Importance and Impact, International Journal of Project Management, Vol. 30, No. 7, pp. 817-826.

Kadri, R.L. and Boctor, F.F. (2018) An Efficient Genetic Algorithm to Solve the ResourceConstrained Project Scheduling Problem with Transfer Times: The Single Mode Case, European Journal of Operations Research, Vol. 265, No. 2, pp. 454-462.

Karadakis, K., Kaplanidou, K. and Karlis, G. (2010) Event Leveraging of Mega Sport Events: A Swot Analysis Approach, International Journal of Event and Festival Management, Vol. 1, No. 3, pp. 170-185.

Khan, K.I.A, Flanagan, F. and Lu, S-L. (2016) Managing Information Complexity Using System Dynamics on Construction Projects, Construction Management and Economics, Vol. 34, No. 3, pp. 1-13. 
Kim, M.K., Kim, S-K., Park, J, A., Carroll, M., Yu, J-G. and Na, K. (2017) Measuring the economic impacts of major sports events: the case of Formula One Grand Prix (F1), Asia Pacific Journal of Tourism Research, Vol. 22, No. 1, pp. 64-73. DOI: https://doi.org/10.1080/10941665.2016.1176061

Kruger, M. and Saayman, M. (2012) Creating a Memorable Spectator Experience at the Two Oceans Marathon, Journal of Sport and Tourism, Vol. 17, No. 1, pp. 63-77.

Lee, C. and Taylor, T. (2005) Critical Reflections on the Economic Impact Assessment of a MegaEvent: The Case of 2002 FIFA World Cup, Tourism Management, Vol. 26, No. 4, pp. 595603.

Leopkey, B., Mutter, O. and Parent, M. (2010) Barriers and Facilitators When Hosting Sporting Events: Exploring the Canadian and Swiss Sport Event Hosting Policies, International Journal of Sport Policy and Politics, Vol. 2, No. 2, pp. 113-134.

Li, S., Blake, A. and Thomas, R. (2013) Modelling the Economic Impact of Sports Events: The Case of the Beijing Olympics, Economic Modelling, Vol. 30, pp. 235-244.

Liang, Y., Wang, C., Tsaur, S., Yen, C. and Tu, J. (2016) Mega-Event and Urban Sustainable Development, International Journal of Event and Festival Management, Vol. 7, No. 3, pp. 152-171.

Liping, W. and Hsin-Hui, L. (2017) Not a One-Size-Fits-All Methodology: A Survey of Mixed Methods, Journal of Advances in Education Research, Vol. 2, No. 2, pp. 97-102.

Low, K.C.P. (2009) How to Win Big in Place Marketing Battlefield - Formula One Night Race, The Singapore Perspective, Business Journal for Entrepreneurs, No. 4, pp. 115-125.

Ma, S., Egan, D., Rotherham, I. and Ma, S. (2011) A Framework for Monitoring During the Planning Stage for a Sports Mega-Event, Journal of Sustainable Tourism, Vol. 19, No. 1, pp. 79-96.

Macleod, G. and Ward, K. (2002) Spaces of Utopia And Dystopia: Landscaping the Contemporary City, Geografiska Annaler, Series B: Human Geography, Vol. 84, No. 3and4, pp. 153-170.

Malfas, M., Theodoraki, E. and Houlihan, B. (2004) Impacts of the Olympic Games as MegaEvents, Municipal Engineer, Vol. 157, No. 3, pp. 209-220.

Marx, M. (2011) The Firm Strikes Back: Non-compete Agreements and the Mobility of Technical Professionals, American Sociological Review, Vol. 76, No. 5, pp. 695-712. 
Meng, W. (2017) Formula One: Singapore Grand Prix Signs 4-Year Extension to Host Night Race, The Straits Times. Available Via: Http://Www.Straitstimes.Com/Sport/FormulaOne/Formula-One-Singapore-Grand-Prix-Signs-Four-Year-Extension-To-Host-NightRace [Accessed: June 2018].

Mills, B. and Rosentraub, M. (2013) Hosting Mega-Events: A Guide to the Evaluation of Development Effects in Integrated Metropolitan Regions, Tourism Management, Vol. 34, pp. 238-246.

Minou C.A., Keizer, O., Teunter, R.H. and Veldman, J. (2017) Joint Condition-based Maintenance and Inventory Optimization for Systems with Multiple Components, European Journal of Operational Research, Vol. 257, No. 1, pp. 209-222.

Müller, M. (2015) The Mega-Event Syndrome: Why So Much Goes Wrong in Mega-Event Planning and What to do About it, Journal of the American Planning Association, Vol. 81, No. 1, pp. 6-17

Næss, H. (2017) Sandwiched Between Sport and Politics: Fédération Internationale De L'automobile, Formula 1, and Non-Democratic Regimes, The International Journal of The History of Sport, pp. 1-19.

Pengelly, M. (2013) Superdome Power Outage Blamed on 'Abnormality in the System', the Guardian. Available Via: Https://Www.Theguardian.Com/Sport/2013/Feb/04/SuperBowl-Xlvii-Power-Outage-Superdome?Intcmp=239andguni=Article:In\%20body\%20link [Accessed: June 2018].

Pizam, A., Shapoval, V. and Ellis, T. (2016) Customer Satisfaction and its Measurement in Hospitality Enterprises: A Revisit And Update, International Journal of Contemporary Hospitality Management, Vol. 28, No. 1, pp. 2-35.

Quester, P. and Farrelly, F. (1998) Brand association and memory decay effects of sponsorship:: the case of the Australian Formula One Grand Prix, Journal of Product and Brand $\begin{array}{lllllll}\text { Management, } & \text { Vol. } & \text { 7, } & \text { No. } & 639-556 . & \text { DoI: }\end{array}$ https://doi.org/10.1108/10610429810244693

Quester, P.G. (1997) Awareness as a measure of sponsorship effectiveness: the Adelaide Formula One Grand Prix and evidence of incidental ambush effects, Journal of Marketing Communications, Vol. 3, No. 1, pp. 1-20. DOI: https://doi.org/10.1080/135272697346014 
Ramchandani, N. (2017) F1 to Rev up Singapore's Events Calendar Till 2021, The Business Times. Available Via: Http://Www.Businesstimes.Com.Sg/Life-Culture/F1-To-Rev-UpSingapores-Events-Calendar-Till-2021 [Accessed: June 2018].

Ritchie, J. and Crouch, G. (2006) The Competitive Destination. Wallingford, Oxon: Cabi.

Samanta, P., Kim, I., Uryasev, S., Penoyar, J. and Vesely, W. (1994) Emergency Diesel Generator: Maintenance and Failure Unavailability, and their Risk Impacts, US Department of Energy. Available via: https://www.osti.gov/biblio/10196692-emergency-diesel-generatormaintenance-failure-unavailability-risk-impacts [Accessed: July 2018].

Shenhar A.J. and Wideman, R.M (2000) Optimizing Project Success by Matching PM Style with Project Type. Available Via: https://www.researchgate.net/publication/255033673_Optimizing_Project_Success_by Matching_PM_Style_with_Project_Type [Accessed: June 2018].

Shepard, F. D. and Cottrell, B. H. (1986) Benefits and Safety Impact of Night Work Zone Activities, Transportation Research Record 1086, Transportation Research Board, Washington D.C., pp $31-36$.

Smith, A. (2013) Leveraging Sport Mega-Events: New Model or Convenient Justification?, Journal of Policy Research in Tourism, Leisure and Events, Vol. 6, No. 1, pp. 15-30.

Song, X., Xu, J., Shen, C. and Peña-Mora, F. (2016a) Conflicts Resolution Based Construction Temporary Facilities Layout Planning in Large-Scale Construction Projects, Canadian Journal of Civil Engineering, Vol. 43, No. 9, pp. 783-801.

Song, X., Xu, J., Shen, C., Peña-Mora, F. and Zeng, Z. (2016b) A Decision Making System for Construction Temporary Facilities Layout Planning in Large-Scale Construction Projects, International Journal Of Civil Engineering, Vol. 15, No. 2, pp. 333-353.

Springer (2013) Megacity Mobility Culture. Heidelberg: Springer.

Spurgeon, B. (2017) Singapore Grand Prix: A Showcase Like No Other, NY Times. Available Via: Http://Www.Nytimes.Com/2013/09/21/Sports/Autoracing/Singapore-Grand-Prix-AShowcase-Like-No-Other.Html [Accessed: May 2018].

Thomas, M. and Adams, J. (2005) Adapting Project Management Processes to the Management of Special Events: An Exploratory Study, Academy of Strategic Management Journal, Vol. 4, pp. 99-114. 
Tng, S. and Tan, S. (2012) Designing Our City: Planning for Sustainable Singapore, Singapore: URA.

Todd, L., Leask, A. and Fyall, A. (2015) Destination Competitiveness: A Comparative Study of Hong Kong, Macau, and Singapore, Tourism Analysis, Vol. 20, No. 6, pp. 593-605.

Van Grootel, L., Van Wesel, F., O'mara-Eves, A., Thomas, J., Hox, J. and Boeije, H. (2017) Using The Realist Perspective to Link Theory from Qualitative Evidence Synthesis to Quantitative Studies: Broadening the Matrix Approach, Research Synthesis Methods, Vol. 8, No. 3, pp. 303-311.

Yang, W. and Mattila, A. (2016) Why do we Buy Luxury Experiences?, International Journal of Contemporary Hospitality Management, Vol. 28, No. 9, pp. 1848-1867.

Zagnoli, P. and Radicchi, E. (2009) Do Major Sports Events Enhance Tourism Destinations?, Physical Culture and Sport, Studies and Research, Vol. 47, No. 1, pp. 4463.

Zeng, J., An, M. and Smith, N. (2007) Application of a Fuzzy Based Decision Making Methodology to Construction Project Risk Assessment, International Journal of Project Management, Vol. 25, No. 6, pp. 589-600.

Zhang, L. (2017) Roads in Marina Centre to be Closed from Sept 13 to 19 for F1 Race, The Straits Times. Available Via: Http://Www.Straitstimes.Com/Singapore/Roads-In-Marina-CentreTo-Be-Closed-From-Sept-13-To-19-In-For-F1-Race [Accessed: May 2018].

Zhou, Y. (2010) Resident perceptions toward the impacts of the Macao Grand Prix, Journal of Convention and Events Tourism, Vol. 11., No. 2, pp. 138-153. DOI: https://doi.org/10.1080/15470148.2010.485179 
Table 1 - Thematic Groupings for Complexity Issue Reporting

\begin{tabular}{|c|c|c|}
\hline Complexity Issues & Complexity Sub-issues & Citations \\
\hline Structures and infrastructure. & $\begin{array}{l}\text { Transportable buildings and toilets; } \\
\text { temporary pedestrian overpasses; } \\
\text { temporary offices (Medical, Energy and } \\
\text { Operations) and fencing works. }\end{array}$ & $\begin{array}{l}\text { (Song et al., } \\
\text { 2016a; Song et al., } \\
\text { 2016b) }\end{array}$ \\
\hline Track and civil installation. & $\begin{array}{l}\text { Track barrier installation; track } \\
\text { cleaning; } \\
\text { ground protection; landscaping and } \\
\text { track cleaning/ sweeping; housekeeping } \\
\text { and traffic management. }\end{array}$ & $\begin{array}{l}\text { (Zhang, } \\
\text { Macleod }\end{array}$ \\
\hline Event facilities and amenities. & $\begin{array}{l}\text { Fittings, furnishings and equipment; } \\
\text { marquees and associated equipment; } \\
\text { hospitality suite extension; circuit } \\
\text { grandstands and paddock areas. }\end{array}$ & $\begin{array}{l}\text { (Browning, 2016; } \\
\text { Pizam et al., 2016) }\end{array}$ \\
\hline $\begin{array}{l}\text { Power/communications/lighting } \\
\text { and miscellaneous. }\end{array}$ & $\begin{array}{l}\text { Super screens; race communication } \\
\text { systems; diesel generator operation; } \\
\text { public lighting systems and telecoms. }\end{array}$ & $\begin{array}{l}\text { (Spurgeon, 2017; } \\
\text { Samanta et al., } \\
\text { 1994) }\end{array}$ \\
\hline Health and safety & $\begin{array}{l}\text { Site inspections and safety } \\
\text { observations; incident and accident } \\
\text { analysis; recommendations for } \\
\text { improvement. }\end{array}$ & (Grant, 2016) \\
\hline
\end{tabular}


Figure 1 - Author Influence in the Field of Events Management and Hospitality Studies.

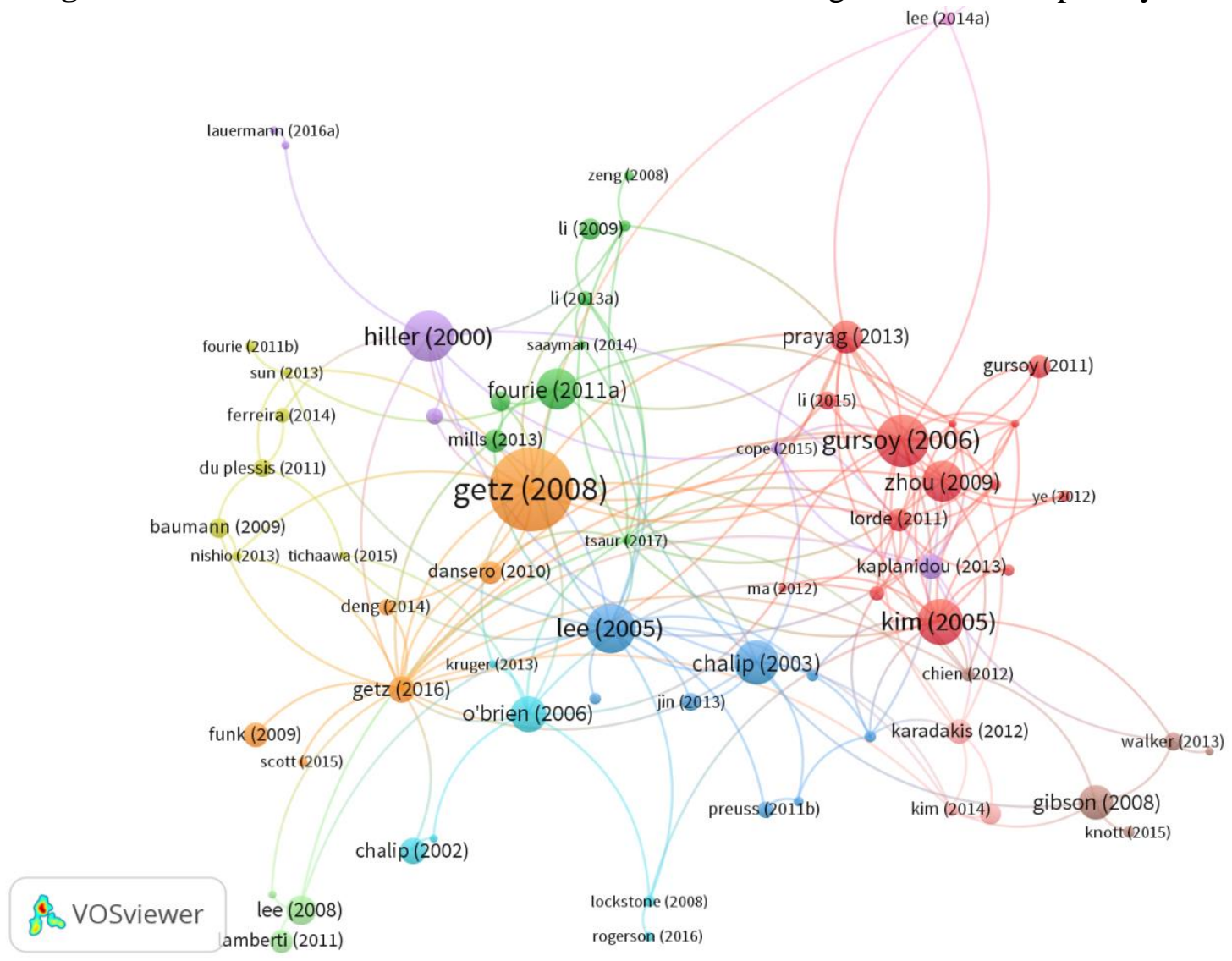


Figure 2 - Contribution of Authors Based on Geographical Regions.

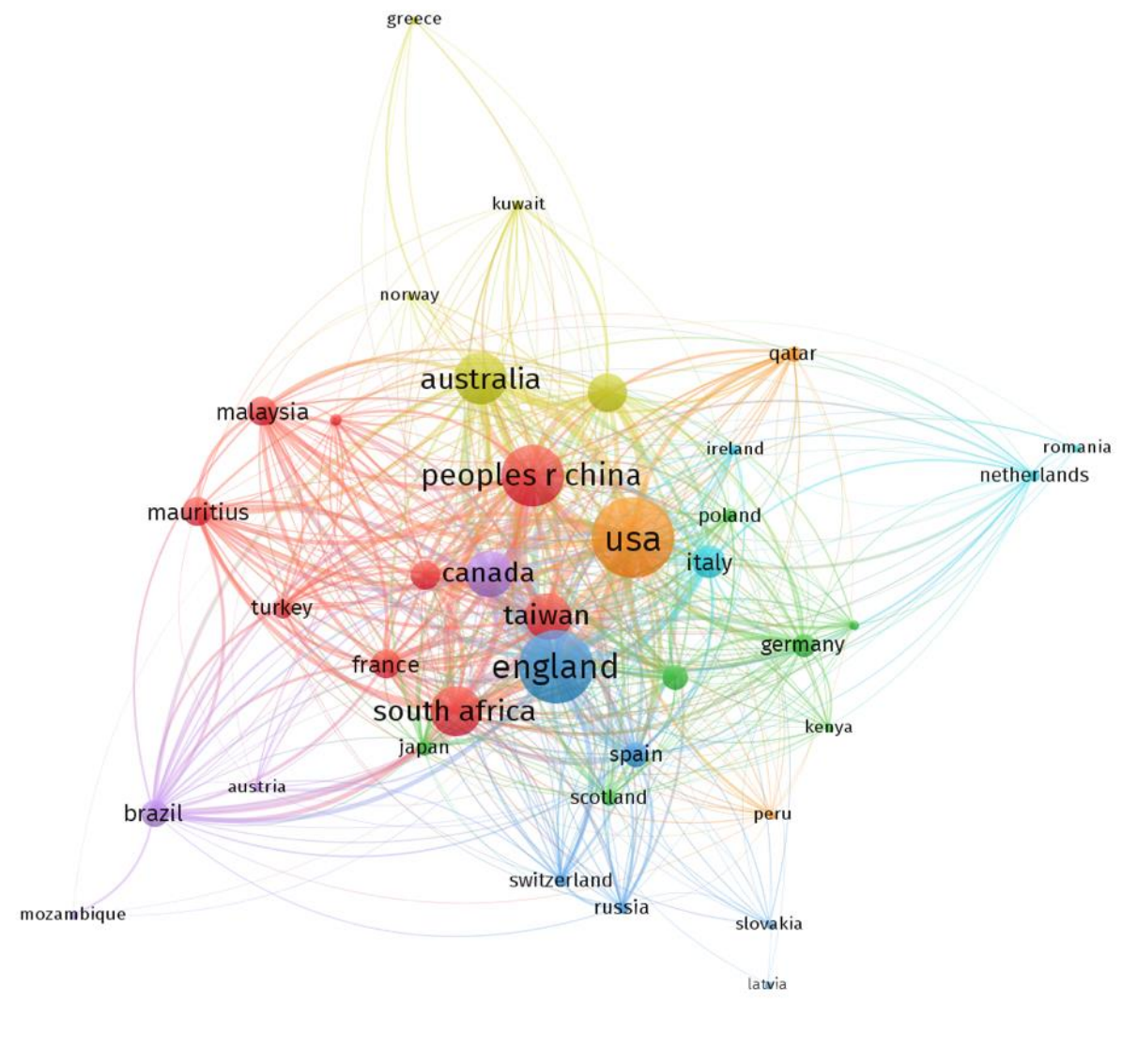


Table 2 - Geographical Distribution of Author Origin

\begin{tabular}{|c|c|c|}
\hline Geographical Region & $\begin{array}{l}\text { Number of } \\
\text { papers }\end{array}$ & $\begin{array}{l}\text { Percentage } \\
\text { Contribution }(\%)\end{array}$ \\
\hline \multicolumn{3}{|l|}{ North and South America } \\
\hline - USA & 55 & 22.63 \\
\hline - Canada & 8 & 3.29 \\
\hline - Brazil & 7 & 2.88 \\
\hline - Barbados & 1 & 0.41 \\
\hline \multicolumn{3}{|l|}{ Asia } \\
\hline - People's Republic of China & 20 & 8.23 \\
\hline - Taiwan & 10 & 4.12 \\
\hline - South Korea & 17 & 7.00 \\
\hline - Japan & 2 & 0.82 \\
\hline - Malaysia & 4 & 1.65 \\
\hline - Turkey & 2 & 0.82 \\
\hline - Qatar & 2 & 0.82 \\
\hline \multicolumn{3}{|l|}{ Europe } \\
\hline - United Kingdom & 25 & 10.29 \\
\hline - Italy & 10 & 4.12 \\
\hline - France & 4 & 1.65 \\
\hline - Portugal & 5 & 2.06 \\
\hline - Spain & 6 & 2.47 \\
\hline - Germany & 8 & 3.29 \\
\hline - Switzerland & 3 & 1.23 \\
\hline - Poland & 2 & 0.82 \\
\hline - Russia & 2 & 0.82 \\
\hline - Netherlands & 4 & 1.65 \\
\hline \multicolumn{3}{|l|}{ Oceania } \\
\hline - Australia & 18 & 7.41 \\
\hline - New Zealand & 8 & 3.29 \\
\hline \multicolumn{3}{|l|}{ Africa } \\
\hline - South Africa & 18 & 7.41 \\
\hline - Mauritius & 2 & 0.82 \\
\hline
\end{tabular}


Figure 3 - Visualisation of Geographical Distribution of Author Origin

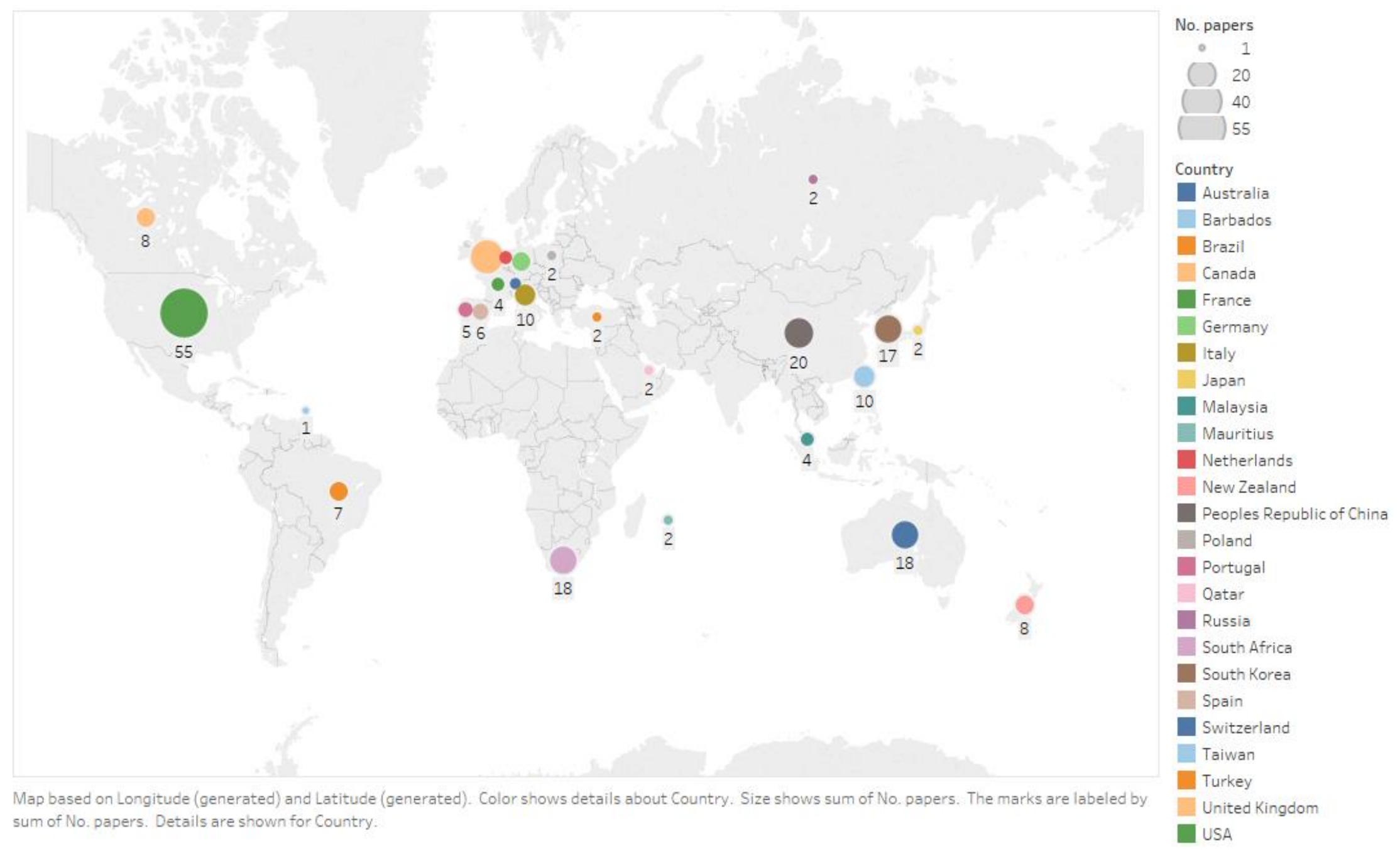


Figure 4 - Research Topics Investigated Over Time

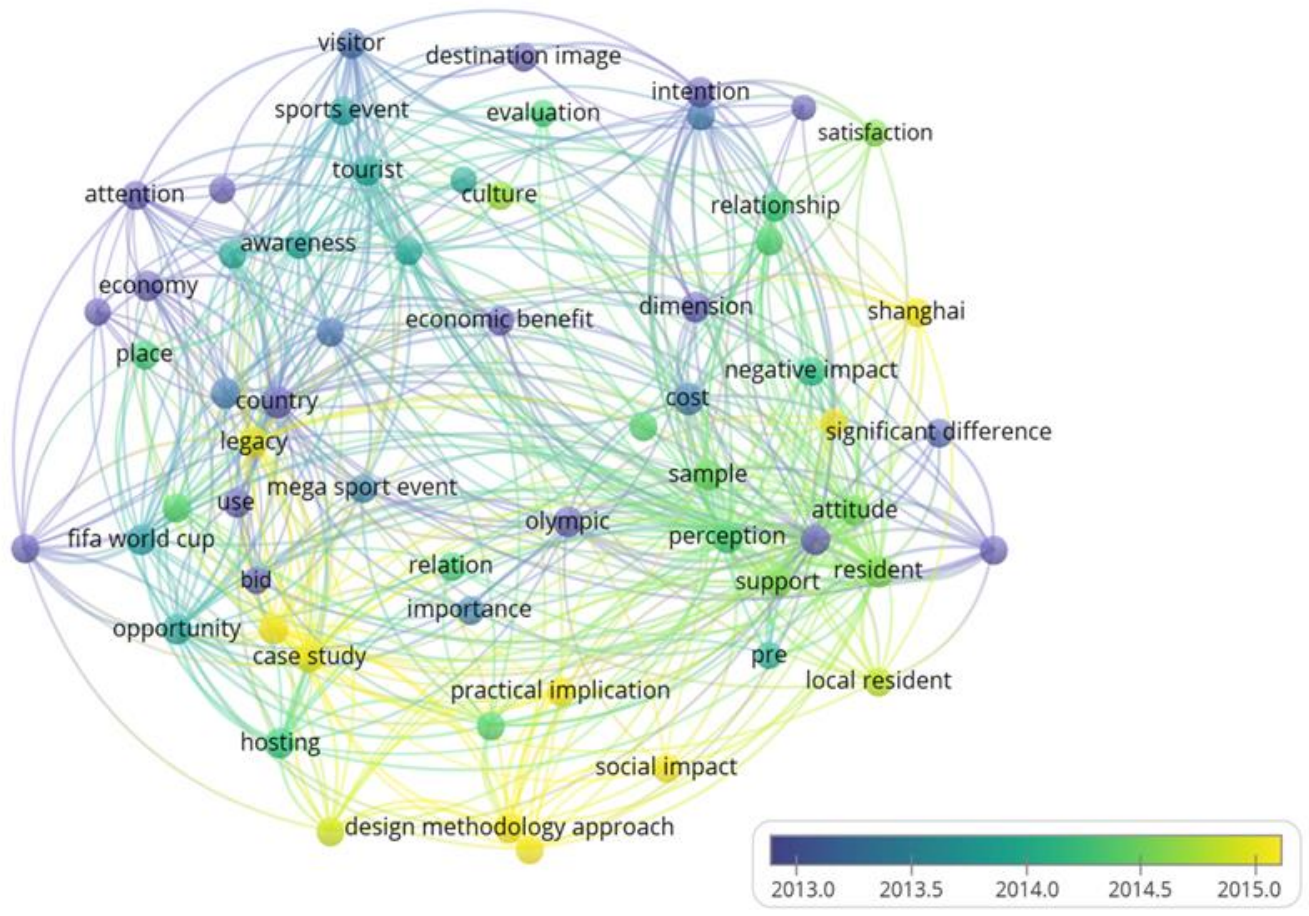


Figure 5 - Enablers and Barriers to Hosting Mega Events Key Terminology

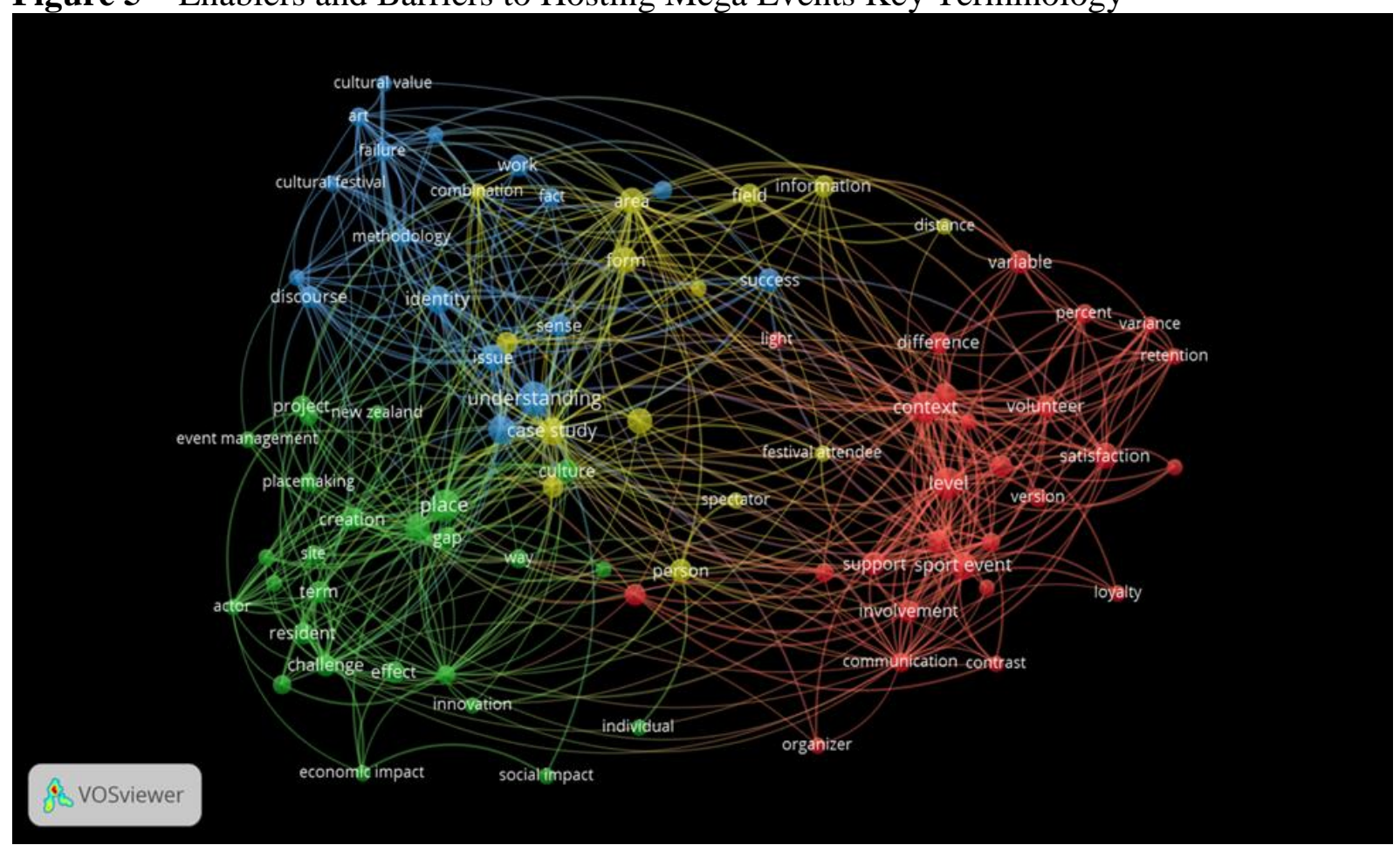

